\title{
Early and midterm patency of the proximal anastomoses of saphenous vein grafts made with a Symmetry Aortic Connector System
}

Hideki Kitamura, MD, Hitoshi Okabayashi, PhD, Michiya Hanyu, PhD, Yoshiharu Soga, PhD, Takuya Nomoto, PhD, Hiroyuki Johno, MD, Jota Nakano, MD, Takehiko Matsuo, MD, Masashi Kai, MD, and Eitaro Umehara, MD

Objective: The purpose of this study was to investigate (1) the early and midterm patency rates in saphenous vein grafts that were anastomosed with the Symmetry Aortic Connector System (St Jude Medical, Inc, St Paul, Minn) and (2) risk factors for graft occlusion.

Methods: Thirty-one patients underwent off-pump coronary artery bypass grafting for proximal saphenous vein graft anastomoses with the aortic connector system. Intraoperative graft flow was studied with transit time flowmetry, and angiography was performed before discharge in 29 cases. Midterm (at least 1 year after the operation) saphenous vein graft patency was assessed by coronary angiography or 3-dimensional coronary computed tomography in 27 cases.

Results: Postoperative angiography demonstrated a $100 \%$ patency rate and no significant stenosis at the connector-anastomosed sites. The 1-year patency rate of the saphenous vein grafts with the aortic connector system was $92.6 \%$, with 2 cases of saphenous vein graft occlusion. Both of these cases had low graft flow and poor left ventricular function documented during the operation.

Conclusion: Once surgical errors had been ruled out, the 1-year patency rate of proximal saphenous vein grafts anastomosed with the aortic connector system was favorable. Poor left ventricular function and low graft flow during the operation were risk factors for midterm graft occlusion. Selection of the target vessel and its runoff may also be an important determinant of long-term patency.

From the Department of Cardiovascular Surgery, Kokura Memorial Hospital, Kitakyusyu City, Fukuoka, Japan.

Received for publication March 17, 2005; revisions received May 22, 2005; accepted for publication May 22, 2005 .

Address for reprints: Hideki Kitamura, MD, Cardiovascular Surgery, Kokura Memorial Hospital, Kifunemachi 1-1, Kokurakitaku, Kitakyusyu City, Fukuoka, 802-8555, Japan (E-mail: k-hideki@sc4.sonet.ne.jp).

J Thorac Cardiovasc Surg 2005;130:1028-31

$0022-5223 / \$ 30.00$

Copyright () 2005 by The American Association for Thoracic Surgery

doi:10.1016/j.jtcvs.2005.05.026

$\mathrm{T}$ he Symmetry Aortic Connector System (ACS; St Jude Medical, Inc, St Paul, Minn) is a device that can be used to eliminate aortic manipulation during anastomoses of vein grafts. ${ }^{1-3}$ Previous reports have demonstrated that the combination use of off-pump coronary artery bypass grafting (OPCAB) and the ACS resulted in a lower rate of postoperative cerebrovascular events. ${ }^{4-6}$ However, the patency rates of grafts placed with the assistance of the ACS remain controversial, ${ }^{7-11}$ with some reports showing a high incidence of graft occlusion when using the ACS for anastomoses. ${ }^{12-16}$ The goal of this study was to investigate the early and midterm patency rates of ACS grafts and to characterize risk factors associated with midterm graft occlusion.

\section{Material and Methods}

From May 2002 to June 2003, a total of 387 patients underwent isolated OPCAB by the same surgeon at our institution. Total arterial revascularization, including the gastroepiploic artery, was used for treatment of multivessel disease. ${ }^{17,18}$ When the gastroepiploic artery was not available or was ill-suited for use as a graft, ${ }^{19}$ revascularization was achieved with saphenous vein grafts (SVGs). In patients with calcification or atheroma of the ascending aorta, aortic clamping was deferred in favor of proximal anastomoses with the ACS. Of a total of 387 
TABLE 1. Clinical profile of 31 patients

\begin{tabular}{lc}
\hline Age (y) & \\
$\quad$ Mean \pm SD & $69.7 \pm 9.9$ \\
$\quad$ Range & $48-86$ \\
Female (No.) & $9(29.0 \%)$ \\
Ejection fraction (\%) & \\
$\quad$ Mean \pm SD & $60.9 \% \pm 12.8 \%$ \\
$\quad$ Range & $33 \%-78 \%$ \\
Left main trunk stenosis (No.) & $14(45.2 \%)$ \\
Three-vessel disease (No.) & $20(64.5 \%)$ \\
Two-vessel disease (No.) & $11(35.5 \%)$ \\
Emergency operation (No.) & $5(16.1 \%)$ \\
Preoperative intra-aortic balloon pump (No.) & $3(9.7 \%)$ \\
Previous coronary artery bypass grafting (No.) & $3(9.7 \%)$ \\
Previous percutaneous coronary intervention & $19(61.3 \%)$ \\
$\quad$ (No.) & \\
Old myocardial infarction (No.) & $13(41.9 \%)$ \\
Hypertension (No.) & $24(77.4 \%)$ \\
Diabetes mellitus (No.) & $12(38.7 \%)$ \\
Hyperlipidemia (No.) & $18(58.1 \%)$ \\
Chronic renal failure (No.) & $4(12.9 \%)$ \\
\hline
\end{tabular}

cases, 31 patients underwent proximal SVG anastomoses with the ACS and were evaluated for this study. Emergency cases were defined as any cases in which diagnosis and subsequent surgery took place on the same day.

\section{OPCAB Procedures}

The saphenous vein was harvested by trained surgeons with the open technique. Heparin $(1 \mathrm{mg} / \mathrm{kg})$ was used to maintain activated clotting time at greater than 250 seconds and was halfway reversed with protamine in nearly all cases after anastomosis. Veins were mounted on the correctly sized device by the primary surgeon according to diameter. Proximal anastomoses were performed first, followed by distal anastomoses. Anastomoses were performed with 7-0 polypropylene continuous suture and assisted by Octopus mechanical stabilization (Medtronic Inc, Minneapolis, Minn).

\section{Graft Evaluation}

Intraoperative graft flow was evaluated with a flowmeter (CardioMeds; Medi-Stim, Oslo, Norway) according to the transit time principle. Angiographic evaluation of graft patency was performed before hospital discharge in 29 cases.

\section{Anticoagulation and Antiplatelet Treatments}

Heparin $(200 \mathrm{U} / \mathrm{kg}$ ) was administered routinely on postoperative days 1 through 4 . Postoperative medical therapy included aspirin $(100 \mathrm{mg} / \mathrm{d}$ orally) in all cases. Other antiplatelet drugs or warfarin sodium were given to 8 patients because of coexisting arterial disease or atrial fibrillation.

\section{Postoperative Follow-up and Graft Evaluation}

Postoperative information was obtained by direct contact with the patients or through telephone conversations with patients or their families. Three-dimensional computed tomography (SOMATOM Sensation 16; Siemens AG, Munich, Germany) was performed at

\section{TABLE 2. Operative details for 31 patients}

\begin{tabular}{lc}
\hline Internal thoracic artery grafts (No.) & 24 \\
Left & 17 \\
Right & 1 \\
Gastroepiploic artery graft (No.) & 31 \\
SVGs (No.) & 108 \\
Total distal anastomoses (No.) & $3.48 \pm 1.15$ \\
Distal anastomoses per patient & \\
ACS size (mm) & $24(77.4 \%)$ \\
$4.5-5.0$ (No.) & $5(16.1 \%)$ \\
$5.0-5.5$ (No.) & $2(6.5 \%)$ \\
$5.5-6.0$ (No.) & $47.3 \pm 19.8$ \\
Intraoperative SVG flow (mL/min) & $9.9-81$ \\
Mean \pm SD & 17 \\
Range & 5 \\
Target coronary arteries for SVG (No.) & 4 \\
Right & 1 \\
Right and circumflex & 1 \\
Circumflex & 1 \\
Left anterior descending & 1 \\
Left anterior descending and circumflex & 1 \\
Right and diagonal & \\
Circumflex and diagonal & \\
Diagonal & \\
\hline
\end{tabular}

ACS, Aortic Connector System; SVG, saphenous vein graft.

least 1 year after the operation in 26 cases, and those results were evaluated by a reliable radiologist. Coronary angiography was performed in 1 case.

\section{Statistical Analysis}

Data were gathered from clinical records and analyzed with StatView version 5.0 (SAS Institute, Inc, Cary, NC). Numeric data were analyzed with the Mann-Whitney and $t$ tests. Categorical data were analyzed by $\chi^{2}$ analysis. Results are expressed as mean \pm SD.

\section{Results}

Preoperative variables are summarized in Table 1. Mean age at operation was 69.7 years. Mean left ventricular ejection fraction was $60.9 \%$. Operative details are summarized in Table 2. There were no operative or in-hospital deaths, and none of the patients had cerebral infarctions or transient ischemic attacks during hospitalization. Twenty-nine patients underwent postoperative coronary angiography before discharge, with a $100 \%$ patency rate and without significant stenosis for proximal anastomoses performed with the ACS.

The follow-up data gathering rate was $100 \%$, with a mean follow-up of 573 days (range 188-852 days). Three of the patients died during the follow-up period $($ cancer $\mathrm{n}=2$, chronic renal failure $\mathrm{n}=1$ ). The 1 -year survival was $93.5 \%$. Follow-up graft evaluation was performed in 27 cases, demonstrating 2 cases of SVG occlusion. The 1-year SVG patency rate was $92.6 \%$. Perioperative details of occluded grafts and patent grafts are summarized in Table 3. Analysis 
TABLE 3. Details of occluded versus patent grafts

\begin{tabular}{lccc}
\hline Variable & $\begin{array}{c}\text { Occluded } \\
\text { (n = 2) }\end{array}$ & $\begin{array}{c}\text { Patent } \\
(\mathbf{n}=\mathbf{2 5})\end{array}$ & $\boldsymbol{P}$ value \\
\hline Age (y, mean) & 67 & $69.6 \pm 9.4$ & .579 \\
Ejection fraction (\%) & $42 \%$ & $62.9 \% \pm 8.8 \%$ & .0415 \\
Left main trunk stenosis (No.) & 0 & 11 & .603 \\
Emergency operation (No.) & 1 & 4 & .234 \\
Preoperative intra-aortic & 0 & 3 & .603 \\
$\quad$ balloon pump (No.) & & & \\
Previous percutaneous & 2 & 14 & .223 \\
$\quad$ coronary intervention (No.) & & & \\
Old myocardial infarction & 2 & 10 & .100 \\
$\quad$ (No.) & & & \\
Graft flow (mL/min, mean) & 14.5 & $48.9 \pm 18.9$ & .0206 \\
Hypertension (No.) & 1 & 15 & .782 \\
Diabetes mellitus (No.) & 0 & 11 & .223 \\
Hyperlipidemia (No.) & 1 & 15 & .782 \\
Chronic renal failure (No.) & 1 & 2 & .069 \\
Other than aspirin (No.) & 0 & 6 & .432 \\
ACS size (mean) & 5 & $4.63 \pm 0.30$ & .956 \\
\hline
\end{tabular}

SDs are given for means for patent group. ACS, Aortic Connector System.

of the cases of graft occlusion determined that only low graft flow during operation and poor left ventricular function were significant risk factors for graft occlusion $(P=$ .0206 and $P=.0415$, respectively).

\section{Discussion}

Several reports have demonstrated that concomitant use of the ACS and OPCAB in patients undergoing surgical revascularization results in a lower rate of postoperative cerebrovascular events, ${ }^{1-6}$ which is consistent with observations from this study that no patients had cerebral infarctions or transient ischemic attacks during the postoperative period. We therefore believe these techniques to be beneficial even in high-risk cases.

Concerning early graft patency, Donsky and colleagues ${ }^{12}$ reported thrombotic occlusions of ACS sites, and there have been several reports of early occlusion with ACS associated with graft kinking or inadequate graft angle. ${ }^{7,8}$ In this study, results showed acceptable early graft patency. We selected target vessels that seemed to possess enough runoff to distinguish the cause of early occlusion as being from the aortic device rather than from poor runoff. As well as technical aspects, selection of target vessels and routine heparin use might result in good early postoperative patency. The ACS is composed of nitinol, which may cause intimal hyperplasia and lead to midterm stenosis and occlusion. ${ }^{13-16}$ However, the incidences of these events seemed to be higher than with a nitinol stent. ${ }^{20}$ Bergsland and associates ${ }^{13}$ reported that half of the Symmetry grafts were occluded and that an additional 25\% had intraconnector stenosis at a mean of 4.8 postoperative months. By contrast,
Hirayama and colleagues reported that nitinol stent restenosis was observed in only $17 \%$ of cases at 6 months of follow-up. ${ }^{20}$ In this study, early graft patency rate was satisfactory, and midterm occlusion rates did not exceed those reported in the literature for hand-sewn polypropylene sutures. ${ }^{9,21-23}$ We speculated that once technical errors, such as graft kinking or inadequate graft angle, were ruled out in the postoperative course, acceptable midterm graft patency could be expected.

However, statistical analysis demonstrated that poor intraoperative graft flow and poor left ventricular function were significantly associated with midterm graft occlusion. These conditions also meant poor runoff. Selection of target vessels and their runoff thus may also be important to long-term patency.

\section{Conclusion}

Once intraoperative technical errors were eliminated, the midterm patency rate of ACS was acceptable; however, poor runoff contributed to midterm graft occlusion. Selection of target vessels is important for long term patency.

We thank Dr Kenji Makisumi of the Department of Radiology at Kokura Memorial Hospital for performing and interpreting the 3-dimensional computed tomographic studies used in this study.

\section{References}

1. Eckstein FS, Bonilla LF, Englberger L, Immer FF, Berg TA, Schmidli J, et al. The St Jude Medical symmetry aortic connector system for proximal vein graft anastomoses in coronary artery bypass grafting. J Thorac Cardiovasc Surg. 2002;123:777-82.

2. Hornik L, Tenderich G, Minami K, Fassbender D, Schulz TO, Beinert B, et al. First experience with the St Jude Medical, Inc, Symmetry Bypass System (Aortic Connector System). J Thorac Cardiovasc Surg. 2003; 125:414-7.

3. Maisano F, Franze V, Bonis MD, Alfieri O. Off-pump coronary artery surgery with the use of anastomotic devices: an additional tool for the challenging patient. Heart Surg Forum. 2002;5:25-7.

4. Endo M, Benhameid O, Morin JF, Shennib H. Avoiding aortic clamping during coronary artery bypass using an automated anastomotic device. Ann Thorac Surg. 2002;73:1000-1.

5. Eckstein FS, Bonilla LF, Englberger L, Stauffer E, Berg TA, Schmidli $\mathrm{J}$, et al. Minimizing aortic manipulation during OPCAB using the Symmetry aortic connector system for proximal vein graft anastomoses. Ann Thorac Surg. 2001;72:S995-8.

6. Scarborough JE, White W, Derilus FE, Mathew JP, Newman MF, Landolfo KP. Combined use of off-pump technique and a sutureless proximal aortic anastomotic device reduces cerebral microemboli generation during coronary artery bypass grafting. J Thorac Cardiovasc Surg. 2003;126:1561-7.

7. Antona C, Scrofani R, Lemma M, Vanelli P, Mangini A, Danna P, et al. Assessment of an aortosaphenous vein graft anastomotic device in coronary surgery: clinical experience and early angiographic results. Ann Thorac Surg. 2002;74:2101-5.

8. Wiklund L, Bugge M, Berglin E. Angiographic results after the use of a sutureless aortic connector for proximal vein graft anastomoses. Ann Thorac Surg. 2002;73:1993-4.

9. Khan MF, Herzog C, Landenberger K, Martens S, Maataoui A, Ackermann H, et al. MDCT of the proximal anastomoses created by nitinol implants in coronary artery bypass grafting: a retrospective twoobserver evaluation. Eur Radiol. 2005;15:305-11. 
10. Mack MJ, Emery RW, Ley LR, Cole PA, Leonard A, Edgerton JR, et al. Initial experience with proximal anastomoses performed with a mechanical connector. Ann Thorac Surg. 2003;75:1866-71.

11. Katariya K, Yassin S, Tehrani HY, Lombardi P, Masroor S, Salerno TA. Initial experience with sutureless proximal anastomoses performed with a mechanical connector leading to clampless off-pump coronary artery bypass surgery. Ann Thorac Surg. 2004;77:563-8.

12. Donsky AS, Schussler JM, Donsky MS, Roberts WC, Hamman BL. Thrombotic occlusion of the aortic ostia of saphenous venous grafts early after coronary artery bypass grafting by the Symmetry aortic connector system. J Thorac Cardiovasc Surg. 2002;124:397-9.

13. Bergsland J, Hol PK, Lingas PS, Lundblad R, Rein KA, Anderson R, et al. Intraoperative and intermediate-term angiographic results of coronary artery bypass surgery with Symmetry proximal anastomotic device. J Thorac Cardiovasc Surg. 2004;128:718-23.

14. Traverse JH, Mooney MR, Pedersen WR, Madison JD, Flavin TF, Kshettry VR, et al. Clinical, angiographic, and interventional follow-up of patients with aortic saphenous vein graft connectors. Circulation. 2003;108:452-6.

15. Dewey TM, Crumrine K, Herbert MA, Leonard A, Prince SL, Worley $\mathrm{C}$, et al. First-year outcomes of beating heart coronary artery bypass grafting using proximal mechanical connectors. Ann Thorac Surg. 2004;77:1542-9.

16. Melero JM, Porras C, Such M, Olalla E, Alonso J. Severe stenosis of anastomoses by using the Symmetry aortic connector system Ann Thorac Surg. 2004;78:1831-3.
17. Muneretto C, Bisleri G, Negri A, Manfredi J, Metra M, Nodari S, et al. Total arterial myocardial revascularization with composite grafts improves results of coronary surgery in elderly: a prospective randomized comparison with conventional coronary artery bypass surgery. Circulation. 2003;108:29-33.

18. Jegaden O, Eker A, Montagna P, Ossette J, Gevigney GD, Finet G, et al. Risk and results of bypass grafting using bilateral internal mammary and right gastroepiploic arteries. Ann Thorac Surg. 1995;59:95560.

19. Suma H, Isomura T, Horii T, Sato T. Late angiographic result of using the right gastroepiploic artery as a graft. J Thorac Cardiovasc Surg. 2000;120:496-8.

20. Hirayama A, Kodama K, Adachi T, Nanto S, Ohara T, Tamai H, et al. Angiographic and clinical outcome of a new self-expanding intracoronary stent (RADIUS): results from multicenter experience in Japan. Catheter Cardiovasc Interv. 2000;49:401-7.

21. Desai ND, Cohen EA, Naylor CD, Phil D, Fremes SE. A randomized comparison of radial-artery and saphenous-vein coronary bypass grafts. N Engl J Med. 2004;351:2302-9.

22. Goldman S, Zadina K, Moritz T, Ovitt T, Sethi G, Copeland JG, et al. Long-term patency of saphenous vein and left internal mammary artery grafts after coronary artery bypass surgery. J Am Coll Cardiol. 2004;44:2149-56.

23. Fitzgibbon GM, Kafka HP, Leach AJ, Keon WJ, Hooper GD, Burton JR. Coronary bypass graft fate and patient outcome: angiographic follow-up of 5,065 grafts related to survival and reoperation in 1,388 patients during 25 years. J Am Coll Cardiol. 1996;28:616-26.

\section{Availability of Journal back issues}

As a service to our subscribers, copies of back issues of The Journal of Thoracic and Cardiovascular Surgery for the preceding 5 years are maintained and are available for purchase from Elsevier Inc. until inventory is depleted. Please write to Elsevier Inc., Subscription Customer Service, 6277 Sea Harbor Dr, Orlando, FL 32877 , or call $800-654-2452$ or $407-345-4000$ for information on availability of particular issues and prices. 